\title{
High Output Cardiac Failure Caused by Multiple Giant Cutaneous Hemangiomas
}

\author{
Paul Chan, M.D., Ching Ping Lee, M.D.,* \\ and Ying Hsiung LEe, M.D., * F.C.C.P., F.I.C.A.
}

\begin{abstract}
SUMmary
A 59-year-old Chinese woman had multiple giant cutaneous cavernous hemangiomas on her right upper limb which resulted in high output heart failure because they presented as a large peripheral arteriovenous (A-V) fistula. Selective right subclavian arteriography showed extremely hypertrophic arteries of the patient's right arm with a tremendous blood supply to the soft tissues; neither superselective embolization nor surgery seemed applicable to this patient. The patient's heart failure was not satisfactorily controlled by conservative treatment.
\end{abstract}

\section{Key Words:}

Cavernous hemangioma Heart failure

\begin{abstract}
CAVERNOUS hemangioma is well known for its presentation as a 1 peripheral A-V fistula, ${ }^{1}$ however, congestive heart failure resulting from giant cutaneous hemangioma is quite rare. ${ }^{2)-4}$. This represents an example of high output of heart failure because of shunting of a large blood volume. Unless the hemangioma is treated at an early stage, ${ }^{51,6)}$ it will enlarge gradually until heart failure appears, which will become intractable because the underlying problem may be impossible to treat. We report a case of multiple giant cutaneous hemangiomas of the right upper limb which had enlarged progressively since the patient's childhood and caused heart failure in her 50 's.
\end{abstract}

\section{Case Report}

This 59-year-old female was first admitted to our hospital in November 1988 because of exertional dyspnea and cough with blood-tinged sputum off and on for several years. Congestive heart failure was diagnosed by a

From the Department of Cardiovascular Medicine, Taipei Municipal Chung Hsian Hospital and *Division of Cardiovascular Medicine, Chang Gung Medical Center, Taipei, Taiwan.

Mailing address: Paul Chan, M.D., Taipei Municipal Chung Hsiao Hospital, 87, Tung Teh Road, Nankang, Taipei 11502, Taiwan, Republic of China.

Received for publication December 9, 1991.

Accepted March 17, 1992. 


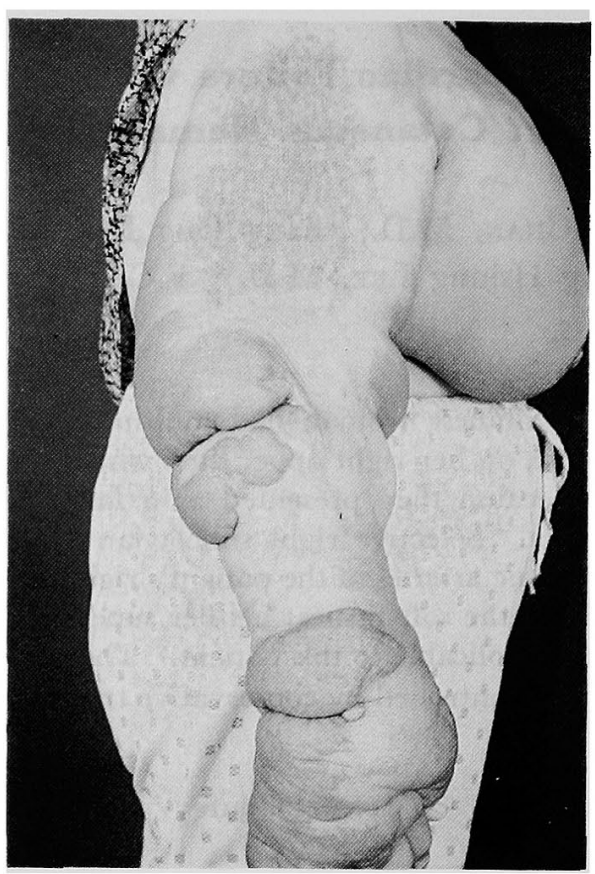

Fig. 1. Lateral view of the hemangiomas.

local physician. Her blood pressure was 140/80 $\mathrm{mmHg}$, and her pulse rate was regular at 80 beats per minute. There was no edema. The heart was enlarged and a grade III/VI systolic murmur was heard. Multiple giant cavernous hemangiomas were noted on her right upper limb with extension to the right anterior chest wall (Fig. 1). Her right upper limb was also markedly hypertrophic and deformed. She said she had had this hemangioma since she was a child, but that it was then much smaller in size. Except for being a cosmetic problem, it had not caused her any difficulty, and she had lived with it quite well. Chest $\mathrm{x}$ ray at that time showed enlargement of the cardiac silhouette with increased pulmonary vascularity and cephalization. The hemogram was normal. After treatment with diuretics, her symptoms improved and she was discharged.

She was followed up regularly at our out-patient clinic until May, 1989 and was admitted again because of progressive worsening of exertional dyspnea and enlargement of her right arm. Blood pressure was 120/70 $\mathrm{mmHg}$, and pulse rate was regular at 90 beats per minute. Chest $\mathrm{x}$ ray revealed a larger cardiac silhouette with bilateral hilar congestion and pleural effusion. Pulmonary edema was suspected. Her symptoms subsided after treatment. The echocardiogram showed an ejection fraction of $77 \%$ with good left ventricular performance. The electrocardiogram was normal. 
Fig. 2A. Arteriogram shows hypertrophy and dolichoectasia of right axillary artery.

2B. Arterial phase of arteriogram shows hypertrophy of branches and multiple tumor vessels.

2C. Persistent tumor stains and multiple foci on the right upper limb.
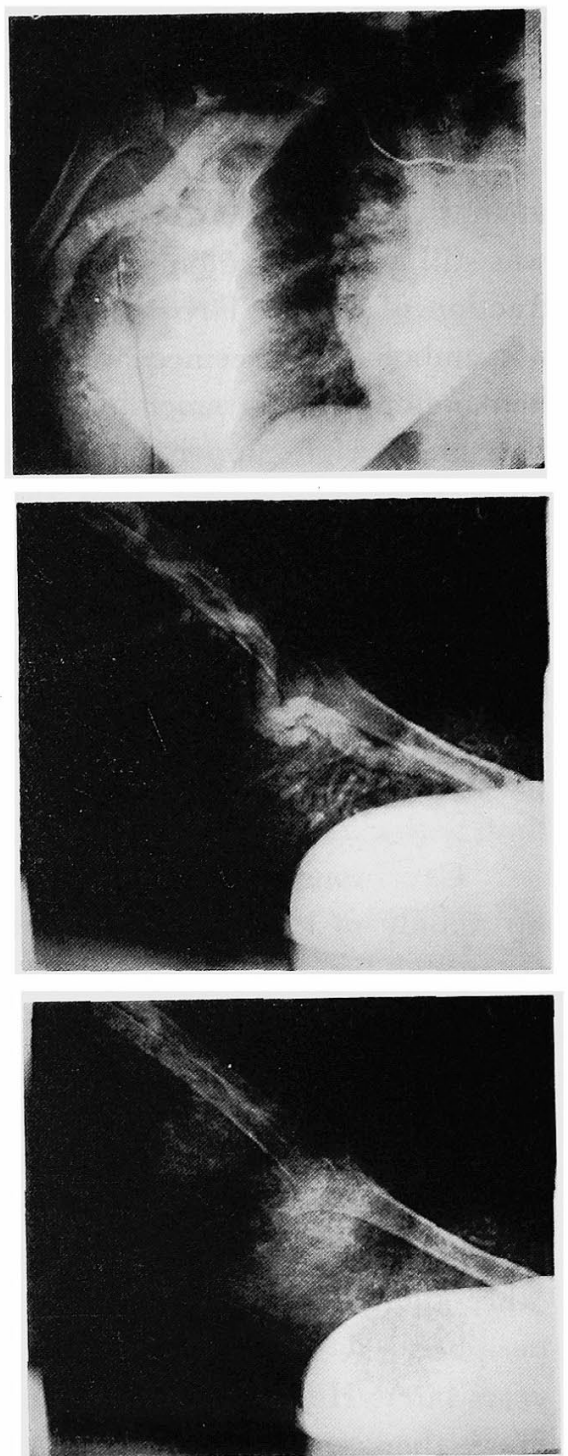

A technetium-99m-pyrophosphate labelled red blood cell whole body radionuclide scan showed a markedly heterogenous distribution of radioactivity over the patient's right arm and right breast. Selective right subclavian angiography (Figs. 2A, B, C) showed extreme hypertrophy of the right subclavian artery and all branches below the axillary artery supplying the hemangioma with marked tumor stains. Cardiac catheterization was considered not to serve any useful purpose.

In September 1989, she was admitted again because of pulmonary 
edema. Cardiac asthma was also noted, which together with the pulmonary edema had been controlled by diuretics and bronchodilators. A pulmonary function test revealed normal lung function, and nonsustained ventricular tachycardia was recorded during that admission. Ejection fraction recorded at that time by echocardiography was $80 \%$ and left ventricular performance was still good. Radionuclide gated-blood pool scanning showed an ejection fraction of $82 \%$. Thyroxine level was normal. Neither surgical treatment nor embolization seemed applicable to this patient because of her extensive hemangioma and tremendous blood supply. The patient refused amputation of her right upper limb. She continues to be treated regularly at our out-patient department even though her symptoms of heart failure have become more difficult to control.

\section{Discussion}

The patient we have described in this paper presented with multiple progressively enlarging giant cavernous hemangiomas of her right upper limb with extension to the right anterior chest wall.

Cavernous hemangioma is a histopathologically benign tumor made up mainly of large venous channels growing deep in the dermis and subcutaneous tissues. Small lesions are seldom disabling and represent only a cosmetic problem. The effective treatment is usually surgery or superselective embolization, especially when the lesion is large. Parenteral steroids are useful in childhood or during the period of rapid growth. ${ }^{71,81}$ However, pathophysiologically the lesion may be malignant if it is large enough to compromise normal hemodynamics such as occurs with hemangiomatous giantism, according to Edgerton's classification, or it may be associated with other abnormalities. ${ }^{\text {g) }}$ In 1957 , Dorney presented his report on a long-term peripheral A-V fistula as a cause of refractory heart failure. ${ }^{10}$ About 10 years later, Holman studied extensively the hemodynamics of A-V shunts. ${ }^{11)}$ Since then several reports on giant cavernous hemangioma causing heart failure have been reported. ${ }^{2)-4)}$ In his paper presented in 1983, Huisman discussed a case similar to ours; however, the location of the cutaneous hemangiomas of his patient were the right thigh and genitals, whereas that of our patient was the right upper extremity and breast. We tried to employ superselective embolization, but the risk of a pulmonary embolism due to the extensive arterial supply was too great. Surgical therapy was also impossible due to the multiple extensive lesions.

The patient's heart failure could be controlled conservatively when she first came to our hospital, but becamc refractory just a half year later because 
of enlargement of the patient's skin lesions. We proposed that the patient's decompensated heart failure was due to the enlargement of hemangiomas which resulted in an increased shunting of blood volume as shown by the increase in ejection fraction at the second admission. In conclusion, we again emphasize that early surgical treatment is important in giant cutancous hemangioma.

\section{REFERENCES}

1. Szilagyi DE, Smith RF, Elliott TP: Congenital arteriovenous abnormalies of the limbs. Arch Surg 111: 423, 1976

2. Huisman RM, Grond J, Van Essen LH: Intractable heart failure resulting from a giant hemangioma. Neth J Med 26: 54, 1983

3. Lofland GK, Filston HC: Giant cutaneous hemangioma associated with axillary arteriovenous fistula causing congestive heart failure in the newborn infant. J Pediatr Surg 22: 456,1987

4. Miall-Allen VM, Morgan B, Cooper P, Shinebourne EA: Peripheral arteriovenous fistula as a cause of neonatal cardiac failure. Intern J Cardiol 10: 177, 1986

5. Stanley R, Buillo E: Nonsurgical treatment of arteriovenous malformations of the trunk and limb by transcatheter arterial embolization. Radiology 115: 609, 1975

6. Coel MN, Alksne JF: Embolization to diminish high output failure secondary to systemic angiomatosis (Ullman's syndrome). Vasc Surg 12: 336, 1978

7. Lasser AE, Stein AF: Steroid treatment of hemangiomas in children. Arch Dermatol 108: 565,1933

8. Edgerton MT: The treatment of hemangiomas: With special references to the role of steroid therapy. Ann Surg 183: 517, 1976

9. Caro WA, Bronstein BR: in Dermatolozy, Vol II, ed by Moschella SL, Hurley HJ, WB Saunders, Philadelphia, p 1595, 1985

10. Dorney ER: Peripheral A-V fistula of fifty-seven years' duration with refractory heart failure. Am Heart J 54: 778, 1957

11. Holman E: Abnormal arteriovenous communications. Circulation 32: 1001, 1965 